\title{
Homenaje de la Sociedad Chilena de Derecho Internacional al Profesor Francisco Orrego Vicuña
}

\author{
Tribute from the Chilean Society of International Law to Professor Francisco Orrego Vicuña
}

\author{
María Teresa Infante Caffi \\ minfante@minrel.gob.cl \\ Embajadora de Chile ante los Países Bajos. Profesora Titular de Derecho Internacional Público, \\ Universidad de Chile.
}

La Sociedad Chilena de Derecho Internacional rinde homenaje a un académico, jurista y servidor público singular, Francisco Orrego Vicuña. Fue también un consejero decisivo para alentar la vocación de muchos estudiantes, abierto a patrocinar a sucesivas generaciones de jóvenes investigadores y profesionales. Nunca dejó de interesarse por nuevos temas, y promovió en sus estudiantes la curiosidad para seguir formándose y enfrentar desafíos de nuevos proyectos.

Sirvió al Instituto de Estudios Internacionales de la Universidad de Chile, como su director, y a nuestro país como diplomático, jurista y asesor. En esas posiciones construyó amplias relaciones con distintas personalidades de nuestra sociedad y de la comunidad internacional, que tempranamente conoció desde sus funciones en la Organización de los Estados Americanos. Después, a lo largo de los años, sería designado árbitro internacional, juez ad hoc, y se lo consultaría en calidad de experto en innumerables oportunidades.

Siempre mostró un alto sentido del interés nacional, y su colaboración inclusive en etapas difíciles de las relaciones exteriores de nuestro país nunca cesó, y merece ser destacada por su consistencia y altura. Sirvió como embajador en Londres entre 1983 y 1985, sin cejar en su empeño de aportar al reencuentro en este país y de reflexionar sobre los pasos para ello.

Su trayectoria en el ámbito del derecho internacional, que combinó con otro particular interés, el de conocer nuestro territorio y sus facetas incógnitas, lo llevaron a variados confines y a lograr un amplio reconocimiento internacional. Fue elegido miembro del Instituto de Derecho Internacional en 1991, y más tarde su presidente en 2005, iniciando un período que culminó con la recordada sesión en octubre de 2007 en Santiago. La resolución del Instituto en 1997, sobre "Responsabilidad por daño al medio ambiente en el derecho internacional", fue fruto de su

Número de página no utilizable para citar 
trabajo como ponente y en ella reflejaría el conocimiento de las distintas variantes que ese tema presentaba en la época, tanto para los estados, como los operadores.

Su gran capacidad intelectual para vincular temas y conversar con personajes de la más variada formación, hicieron conocido a Francisco Orrego Vicuña como una persona independiente y con liderazgo, así como dotado de habilidades para generar acuerdos en situaciones difíciles. Esa faceta se demostró al crear el Consejo Chileno para las Relaciones Internacionales y convocar a una serie de grupos de trabajo sobre temas diversos de la política exterior, vitales en la etapa de restablecimiento de la democracia en Chile, dando tribuna a personalidades que animaron el ambiente intelectual, político y diplomático de nuestro país. Fue un punto culminante de su trayectoria a nivel nacional.

Ese sello fue reconocido en sucesivas etapas de su vida, la que se fue reflejando en obras y proyectos. Recordemos entre otras actuaciones, su participación en la Comisión para la Solución de Controversias entre Chile y Estados Unidos sobre el Caso Letelier Moffit, cuya decisión fue emitida en enero de 1992. Una reflexión interesante sobre el derecho internacional aplicable y su relación con la justicia puede leerse en su opinión separada concurrente con la decisión adoptada.

Unos años antes, había sido llamado a participar en el equipo de la Mediación Pontificia con Argentina, cuyo inicio hace cuarenta años hemos celebrado en estos días. También se lo invitó a co-presidir la delegación chilena a la III Conferencia de las Naciones Unidas sobre el Derecho del Mar, junto a otro avezado diplomático, el embajador Fernando Zegers. Recordamos la tenacidad desplegada por el profesor Orrego Vicuña al presentar una propuesta sobre el jus cogens y como se logró la fórmula que actualmente contiene el artículo 311 (3) de la Convención de las Naciones Unidas sobre el Derecho del Mar.

Su capacidad para actuar como asesor nunca interfirió con la creación académica y el desarrollo de otras acciones en el ámbito internacional. Desde su temprana vida profesional, una interesante producción sobre integración latinoamericana y el derecho del mar, lo vinculó con el ambiente jurídico interamericano. Al retornar de la OEA en los años setenta, y cuando la Universidad de Chile vivía momentos y definiciones que requerían rigor y decisión, el profesor Orrego trabajó intensamente por la autonomía del Instituto de Estudios Internacionales, dotándolo de un cuerpo académico de valor e inserto en las realidades regionales y nacionales. Cultivó también la enseñanza de alta calidad en la Facultad de Derecho de la misma Universidad.

Entre los años 1974 y 1983 se desempeñó como director del Instituto de Estudios Internacionales, aportando en la Universidad un sello de calidad, tolerancia e independencia ampliamente valorado en nuestro medio.

Número de página no utilizable para citar 
Su presencia y labor permitió dar continuidad a revista Estudios Internacionales e introducir de forma más sistemática el derecho internacional en el desarrollo académico del Instituto y la Universidad, junto al cultivo de las relaciones internacionales, los estudios sobre política exterior y las relaciones económicas internacionales. Recordemos que en el Instituto se llevó a cabo un primer seminario sobre el papel de los derechos humanos en las relaciones internacionales, que integró perspectivas de especialistas chilenos y extranjeros.

Francisco Orrego Vicuña formó también parte de una generación, todavía activa, que buscó la implementación creativa y dinámica, del Tratado de Paz y Amistad con Argentina, de 1984, celebrado al amparo de la mediación pontificia al término de un largo proceso de negociación, precedido de dramáticas jornadas.

Así, en la década de los ochenta y comienzo de los noventa, aportó de forma decisiva a generar ideas para la construcción de una nueva relación con el vecino país, mediante propuestas concretas de cooperación e integración. Nuevamente, el derecho internacional en sus diversas áreas de aplicación cumpliría un papel señero.

Paralelamente, cultivó relaciones con fundaciones de reconocido prestigio, y asoció su nombre a la proyección de áreas novedosas en las relaciones de Chile con la Cuenca del Pacífico, desde diversas perspectivas. Incluyó las islas oceánicas chilenas como objeto de estudio multidisciplinario y atrajo al mundo científico, de las ciencias sociales y la cultura, a aportar una nueva mirada a la región. La ruta diseñada desde la creación del Instituto de Estudios Internacionales, pocos años antes, se fue así profundizando y consolidando. Su fascinación por la Isla de Pascua lo llevaría a profundizar en sus tesoros culturales y riqueza inmaterial.

Su capacidad para ejecutar proyectos, lo llevó a escribir y editar obras fundamentales que sirven de referencia indudable en la producción bibliográfica chilena y latinoamericana. Desde el punto de vista teórico, en sus años más recientes, y sin rehuir la discusión de fondo, quiso adentrarse en discusiones sobre el consentimiento, la formación de la costumbre y la solución de controversia en el derecho internacional.

Otra manifestación de su creatividad se puede encontrar en el novedoso programa de Maestría en Derecho Internacional que han venido impartiendo la Universidad de Chile y la Universidad de Heidelberg, desde 2004. Allí se ha reflejado el espíritu del profesor Orrego Vicuña y del profesor Rüdiger Wolfrum, del Instituto Max Planck y la Universidad de Heidelberg, prestigiando a nuestro país.

Francisco Orrego Vicuña fue un autor prolífico, escritor de ensayos y editor de obras clásicas en castellano e inglés, sobre temas como la zona económica exclusiva, el derecho y la política de la Antártica, los fondos marinos, la solución de controversias, entre otros. Sus obras 
fundamentales sobre el derecho del mar y los recursos naturales antárticos y el Sistema del Tratado Antártico, se reflejarían en sus estudios de doctorado en el London School of Economics.

En materia antártica, es oportuno recordar que dirigió trascedentes seminarios que encauzaron las negociaciones sobre recursos naturales y la conexión de estos con la protección del medio ambiente, incluyendo las perspectivas de los países del hemisferio sur. Esto llevó a profundizar algunas características que impone el Tratado Antártico, compatibles con el enfoque dual de un país que afirma poseer derechos soberanos, como es el caso de Chile. Igualmente, aportó consejos esenciales para resolver interrogantes acerca de la protección del medio ambiente antártico y la cuestión de los recursos minerales, ante la dispersión de posiciones que se generó en nuestro país al iniciarse la década de los noventa.

Estos atributos llevaron al profesor Orrego Vicuña a publicar en revistas del prestigio del American Journal of International Law, el Anuario Francés de Derecho Internacional, el International and Comparative Law Quarterly, y a enseñar y publicar en la Academia de Derecho Internacional de La Haya, entre otros medios. Fue honrado con el Premio Nacional de Humanidades y Ciencias Sociales en 2001, y presidió la Academia Chilena de Ciencias Sociales, Políticas y Morales entre 1995 y 2000.

En las últimas décadas fue distinguido con la nominación como árbitro en los más importantes sistemas a nivel internacional, integrando el Consejo Internacional de Arbitraje Comercial, y diversos tribunales arbitrales en el marco del Centro Internacional de Arreglo de Diferencias Relativas a Inversiones del Banco Mundial y de otros sistemas, así como un importante panel de solución de controversias en la Organización Mundial del Comercio. Formó parte de los Tribunales Administrativos del Banco Mundial y del Fondo Monetario Internacional. La franqueza y estilo de sus decisiones continuarán siendo objeto de estudio para quienes se adentran en el arbitraje internacional.

En su vida, Francisco Orrego Vicuña tuvo el honor de participar como juez ad hoc en dos casos que Chile enfrentó en tribunales internacionales, el primero ante el Tribunal Internacional del Derecho del Mar por el tema del pez espada con la Unión Europea, y posteriormente en el asunto sobre delimitación marítima planteado por el Perú ante la Corte Internacional de Justicia, y que se tramitó entre 2008 y 2014. Estas designaciones coronaron una vida dedicada a funciones de transcendencia. En La Haya, presentó una contundente opinión, además de sumar su voz a las de otros distinguidos miembros del tribunal en un texto cuya lectura es fundamental para comprender la decisión de la Corte, de enero de 2014.

Nuestro país y la comunidad internacional, el medio académico y los tribunales, han despedido a Francisco Orrego Vicuña como un genuino servidor público, comprometido con la reflexión 
Revista Tribuna Internacional

Volumen $8 \cdot \mathrm{N}^{\mathrm{o}} 15 \cdot 2019$

ISSN 0719-482X (versión en línea)

sobre el derecho internacional y su eficacia. Un intelectual cosmopolita, con amplios conocimientos e intereses, y versátil escritor.

Ha dejado un gran vacío en el medio nacional e internacional y esta Sociedad deberá mantener vivo su recuerdo y obra. A su familia aquí presente, transmitimos la sentida voz de esta Sociedad que destaca la contribución y el ejemplo que se desprende de la vida y obra de Francisco Orrego Vicuña.

Número de página no utilizable para citar 